\title{
Inhaled dry-powder formoterol and salmeterol in asthmatic patients: onset of action, duration of effect and potency
}

\author{
M. Palmqvist*+, G. Persson**, L. Lazer ${ }^{++}$, J. Rosenborg $¥$, P. Larsson $\ddagger$, J. Lötvall*
}

Inhaled dry-powder formoterol and salmeterol in asthmatic patients: onset of action, duration of effect and potency. M. Palmqvist, G. Persson, L. Lazer, J. Rosenborg, P. Larsson, J. Lötvall. COERS Journals Ltd 1997.

ABSTRACT: Salmeterol and formoterol are two long-acting $\beta_{2}$-agonists for inhalation, currently being used in clinical practice. The aim of the present study was to investigate the onset of action, duration of effect and potency of these two $\beta_{2}$ agonists in asthmatic patients.

Patients $(n=28)$ were included on the basis of salbutamol stepwise reversibility $(100,100$ and $200 \mu \mathrm{g}$, given cumulatively; total reversibility $\geq 15 \%)$. In a doubleblind placebo-controlled crossover study, the bronchodilating properties of formoterol 6, 12 and $24 \mu \mathrm{g}$ were compared with the effects of salmeterol $50 \mu \mathrm{g}$. Formoterol was given via Turbuhaler ${ }^{\circledR}$ and salmeterol via Diskhaler ${ }^{\circledR}$, and forced expiratory volume in one second (FEV1) was monitored during $12 \mathrm{~h}$.

Formoterol at all doses had a more rapid onset than salmeterol as judged from bronchodilation at $3 \mathrm{~min}$ after the dose. Formoterol at all doses had a similar duration of effect to salmeterol $50 \mu \mathrm{g}$, as judged from bronchodilation at $12 \mathrm{~h}$ after dose administration. When the relative potency of the two drugs was compared, salmeterol $50 \mu \mathrm{g}$ was estimated to correspond to formoterol $9 \mu \mathrm{g}$ (95\% confidence interval: $3-19 \mu \mathbf{g}$ ).

We confirm that formoterol and salmeterol are both long-acting $\beta_{2}$-agonists, but with some differences in effect profile. We confirm the more rapid onset of action of formoterol compared with salmeterol, and furthermore, no difference in duration of effect is evident.

Eur Respir J 1997; 10: 2484-2489.
Depts of $*$ Clinical Pharmacology and +Respiratory Medicine and Allergology (Centre of Allergy and Asthma Research), University of Göteborg, Sweden. **Dept of Pulmonary Medicine, University of Lund, Sweden. ${ }^{++}$Pulmonary Clinic, Malmö General Hospital, Malmoe, Sweden, Clinical research and Development, Astra Draco, Lund, Sweden.

Correspondence: J. Lötvall

Dept of Clinical Pharmacology

Sahlgrens University Hospital

S-413 45 Göteborg

Sweden

Keywords: Asthma

$\beta_{2}$-agonist

formoterol

salmeterol

onset

potency

Received: November 121996

Accepted after revision September 31997

The study was financed by Astra Draco, Lund, Sweden. JL and MP are partially financed by Herman Krefting's Foundation for Asthma and Allergy Research. $\beta_{2}$-agonists, used by inhalation, have a central role in the treatment of patients with asthma, both as acute and chronic medication. In general, bronchodilation occurs rapidly to inhaled $\beta_{2}$-therapy, but with generally used short-acting $\beta_{2}$-agonists, such as salbutamol and terbutaline, the duration of action is only $4-6 \mathrm{~h}$. For many asthmatic patients, this is not sufficient, particularly when night-time symptoms such as dyspnoea and early morning wheeze cannot be prevented with an evening dose of a short-acting $\beta_{2}$-agonist. Therefore, long-acting $\beta_{2}$-agonists for inhalation, such as formoterol and salmeterol, have been developed. Both these drugs have been shown to cause bronchodilation for at least $12 \mathrm{~h}$ after single dose administration [1-4]. Twice daily treatment with inhaled formoterol or salmeterol has been shown to reduce diurnal airway calibre fluctuations and asthma symptoms [5-7], and inhaled long-acting $\beta_{2}$ agonists are therefore important components in the therapy of patients with chronic asthma, who are not fully controlled with inhaled anti-inflammatory therapy [8].

Both salmeterol and formoterol have been compared with salbutamol or terbutaline. In one study, salbutamol was shown to have a more rapid onset of action than salmeterol [9]. Comparisons between terbutaline and formoterol suggest a rapid onset of action of formoterol [10]. Thus, these previous studies together suggest that formoterol may have a more rapid onset of action than salmeterol.

Only few direct comparisons between salmeterol and formoterol have been presented $[4,11]$, but these studies are limited to the comparison between one or two doses of formoterol and/or salmeterol. In brief, formoterol 12 $\mu \mathrm{g}$ has a greater bronchodilating effect than salmeterol $50 \mu \mathrm{g}$ 1-4 min after inhalation [11], whereas a similar result on forced expiratory volume in one second (FEV1) and bronchial reactivity to methacholine is observed after $30 \mathrm{~min}$ [4].

Because of the limited number of doses in the direct comparisons between formoterol and salmeterol in earlier studies, the present study was performed to clarify the dose relationship and differences between those two drugs. Thus, the aim of the present study was to investigate the onset of action, duration of effect and potency of the bronchodilating effect of formoterol Turbuhaler ${ }^{\circledR}$ (Astra Draco, Lund, Sweden), 6, 12 and $24 \mu \mathrm{g}$, respectively, in comparison with a standard dose of inhaled salmeterol (50 $\mu \mathrm{g}$ - Serevent Diskhaler®, Glaxo Wellcome Ltd, Ware, UK) in asthmatic patients. 
Methods

\section{Patients}

The study was approved by the local Ethics Committees at the centres named below. Twenty eight asthmatic patients (17 females) were recruited at three centres: Sahlgrenska University Hospital (centre 1), Malmö General Hospital (centre 2), and University Hospital Lund (centre 3). Twenty six patients were included and four patients discontinued the study. Two of these attended only one study day, and were not evaluated statistically. Patient data are presented in table 1. All patients were treated with short-acting $\beta_{2}$-agonists as required, and all patients, except two, were treated with inhaled glucocorticoids. The inhaled glucocorticoids used were beclamethasone dipropionate and budesonide (total daily doses ranging 200-1,600 $\mu \mathrm{g}$ ). Slow-release theophylline and/or slow-release $\beta_{2}$-agonist were used by six patients.

\section{Inclusion criteria}

Only nonsmoking stable asthmatic patients (18-70 yrs of age) with FEV1 $>40 \%$ predicted were included. A reversibility of at least $10 \%$ of FEV1 should be seen 30 min after $100 \mu \mathrm{g}$ salbutamol delivered by pressurized metered-dose inhaler (pMDI). An additional increase of FEV1 after a total dose of 200 or $400 \mu \mathrm{g}$ salbutamol pMDI $(100+100+200 \mu \mathrm{g})$ should be at least $50 \%$ of the effect observed with $100 \mu \mathrm{g}$, i.e. patients were only to be included if they had a reversibility of at least $15 \%$ of FEV1 compared with baseline. The reason for this stepwise reversibility was to ensure a dose-response relationship for a bronchodilating drug in the included patients. This stepwise procedure was performed at the separate inclusion visit.

\section{Protocol}

A randomized double-blind, placebo-controlled, crossover, double-dummy design was used, to evaluate the effects of placebo, three different doses of inhaled formoterol $(6,12,24 \mu \mathrm{g}$; given via Turbuhaler®) and a single dose of salmeterol ( $50 \mu \mathrm{g}$; given via the Diskhaler ${ }^{\circledR}$ device). Every second patient started the inhalations with Turbuhaler®, and the others with Diskhaler®. Peak inspiratory flow through the relevant devices was monitored with Vitalograph MDI (Vitalograph Ltd, Buckingham, UK), and was aimed to exceed $50 \mathrm{~L} \cdot \mathrm{min}^{-1}$ with Turbuhaler® and $80 \mathrm{~L} \cdot \mathrm{min}^{-1}$ with Diskhalerß. FEV1 was measured before inhalation of the study drug, and 3, 15, 30 and

Table 1. - Patient characteristics, lung function data and reversibility inclusion data

\begin{tabular}{|c|c|c|c|c|c|c|c|c|}
\hline \multirow[t]{2}{*}{$\begin{array}{c}\text { Patient } \\
\text { No. }\end{array}$} & \multirow[t]{2}{*}{ Sex } & \multirow[t]{2}{*}{$\begin{array}{l}\text { Age } \\
\text { yrs }\end{array}$} & \multirow[t]{2}{*}{$\begin{array}{l}\text { Asthma } \\
\text { medication }\end{array}$} & \multirow[t]{2}{*}{ FEV1 } & \multirow[t]{2}{*}{$\begin{array}{l}\text { FEV1 } \\
\% \text { pred }\end{array}$} & \multicolumn{3}{|c|}{$\begin{array}{c}\text { FEV1 \% reversibility } \\
\text { salbutamol }\end{array}$} \\
\hline & & & & & & $v s$ baseline & vs $0.1 \mathrm{mg}$ & vs $0.1 \mathrm{mg}$ \\
\hline \multicolumn{9}{|c|}{ Centre 1} \\
\hline 1 & $\mathrm{~F}$ & 48 & ISB, IC & 2.24 & 83 & 13 & 100 & \\
\hline 2 & $\mathrm{~F}$ & 60 & ISB, IC, ILB & 1.55 & 62 & 17 & 54 & \\
\hline 3 & $\mathrm{~F}$ & 26 & ISB, IC, ILB & 2.98 & 86 & 11 & 45 & 61 \\
\hline 4 & M & 51 & ISB, IC & 3.35 & 88 & 14 & 59 & \\
\hline 5 & $\mathrm{~F}$ & 61 & ISB, IC, ILB & 2.15 & 112 & 16 & 34 & 83 \\
\hline 6 & $\mathrm{M}$ & 69 & ISB & 2.52 & 86 & 10 & 52 & 60 \\
\hline 7 & $\mathrm{~F}$ & 24 & ISB, IC & 2.56 & 78 & 10 & 31 & 54 \\
\hline 8 & $\mathrm{M}$ & 61 & ISB, IC & 1.75 & 59 & 14 & 72 & \\
\hline 9 & M & 25 & ISB, IC & 3.58 & 80 & 13 & 53 & \\
\hline \multicolumn{9}{|c|}{ Centre 2} \\
\hline 10 & M & 63 & ISB, IC & 1.75 & 58 & 20 & 40 & 57 \\
\hline 11 & M & 66 & ISB & 2.75 & 89 & 17 & 35 & 63 \\
\hline 12 & $\mathrm{~F}$ & 36 & ISB, IC & 1.60 & 62 & 14 & 65 & \\
\hline 13 & $\mathrm{~F}$ & 61 & ISB, IC, ILB, T & 1.98 & 76 & 11 & 64 & \\
\hline 14 & $\mathrm{~F}$ & 55 & ISB, IC, ILB, T & 2.19 & 71 & 12 & 70 & \\
\hline 15 & $\mathrm{~F}$ & 25 & ISB, IC, ILB, OB, T & 2.72 & 64 & 26 & 18 & 49 \\
\hline 16 & M & 36 & ISB, IC, T & 2.38 & 66 & 24 & 39 & 77 \\
\hline 17 & M & 57 & ISB, IC & 2.54 & 61 & 20 & 116 & \\
\hline \multicolumn{9}{|c|}{ Centre 3} \\
\hline 18 & $\mathrm{M}$ & 41 & ISB, IC & 4.06 & 87 & 21 & 20 & 55 \\
\hline 19 & M & 20 & ISB, IC & 2.48 & 71 & 18 & 20 & \\
\hline 20 & $\mathrm{~F}$ & 29 & ISB, IC & 2.48 & 72 & 10 & 96 & \\
\hline 21 & $\mathrm{~F}$ & 32 & ISB, IC & 2.50 & 93 & 16 & 13 & 51 \\
\hline 22 & $\mathrm{~F}$ & 38 & ISB, IC, ILB & 2.34 & 83 & 13 & 45 & 68 \\
\hline 23 & $\mathrm{~F}$ & 40 & ISB, IC & 2.58 & 71 & 11 & 50 & \\
\hline 24 & $\mathrm{~F}$ & 40 & ISB, IC, OB & 2.37 & 83 & 12 & 3 & 62 \\
\hline 25 & $\mathrm{~F}$ & 46 & ISB, IC, T & 1.86 & 69 & 10 & 68 & \\
\hline 26 & $\mathrm{~F}$ & 46 & ISB, IC & 1.53 & 65 & 18 & 33 & 78 \\
\hline 27 & $\mathrm{~F}$ & 66 & ISB, IC & 1.51 & 44 & 19 & 79 & \\
\hline 28 & M & 55 & ISB, IC, ILB & 1.75 & 55 & 17 & 3 & 62 \\
\hline Mean & & & & 2.36 & 74 & 15 & 50 & \\
\hline
\end{tabular}

M: male; F: female; FEV1: forced expiratory volume in one second; $\%$ pred: $\%$ of predicted value; ISB: inhaled shortacting $\beta_{2}$-agonist; IC: inhaled corticosteroid; ILB: inhaled long-acting $\beta_{2}$-agonist; OB: oral $\beta_{2}$-agonist; T: oral theophylline. 
60 min after inhalation, and subsequently every hour up to $12 \mathrm{~h}$. At least $48 \mathrm{~h}$ were required between each visit, and baseline FEV1 on study days was not allowed to vary more than $12 \%$ from the baseline on the screening day. Furthermore, to avoid a carryover effect, baseline FEV1 on a study day should not be more than $15 \%$ higher than the baseline FEV1 of the preceeding study day. If this criterion was not met, the patients were allowed to return once for another attempt. Radialis cardiac frequency and systemic blood pressure sphygmomanometer were monitored before inhalation of the study drug, and $1,2,4,6,8,10$ and $12 \mathrm{~h}$ after inhalation. A followup visit was made within 2 weeks after the last study day.

\section{Data analysis}

The primary objective of this study was to assess the potency of formoterol Turbuhaler ${ }^{\circledR}(6,12,24 \mu \mathrm{g})$, compared with that of salmeterol Diskhaler® $50 \mu \mathrm{g}$. The primary variable for this comparison was the $12 \mathrm{~h}$ average FEV1 (area under the FEV1 versus time curve divided by $12 \mathrm{~h}$ ). Secondary objectives of the study were to compare the onset of action and duration of the effect of formoterol Turbuhaler ${ }^{\circledR}$ and salmeterol Diskhaler ${ }^{\circledR}$.

The primary objective was addressed by using a multiplicative analysis of variance model, including the factors: patient, treatment and period. Baseline FEV1 was used as covariate. The dose of formoterol Turbuhaler ${ }^{\circledR}$ equipotent to salmeterol $50 \mu \mathrm{g}$ Diskhaler® was estimated by fitting a straight line to the adjusted $12 \mathrm{~h}$ average FEV 1 for the three doses of formoterol. The $95 \%$ confidence interval (CI) for the equipotent dose was calculated by using Fieller's method. Onset of action was evaluated using Wilcoxon's signed rank test on the onset time, defined as the interpolated time for the first increase in FEV 1 of at least $15 \%$ over baseline within $1 \mathrm{~h}$ after inhalation. In this evaluation, an onset time of $60 \mathrm{~min}$ was used for patients not showing a $15 \%$ increase within $1 \mathrm{~h}$. Onset was also addressed by comparing the FEV1 measured 3 and $15 \mathrm{~min}$ after inhalation of the study drug. Duration of action was evaluated using Wilcoxon's signed rank test on the duration time, defined as the time from onset (defined as above) until the interpolated time for the first FEV1 under the $15 \%$ increase over baseline. The duration was also evaluated by comparing the residual FEV1 at $12 \mathrm{~h}$. Data are presented as means and variations as SEM.

For the description of time of duration, arithmetic mean data from only responders, reaching improvement of FEV1 of at least $15 \%$ within $1 \mathrm{~h}$ of treatment, are described. However, for the statistical analysis, nonresponders are also included (nonresponders given an onset of $1 \mathrm{~h}$, and duration of 0 ).

\section{Results}

Mean baseline values of FEV1 were: on the placebo day $2.27 \mathrm{~L}$; on the formoterol days (dose administered: 6, 12 and $24 \mu \mathrm{g}) 2.32,2.32,2.26 \mathrm{~L}$, respectively; and on the salmeterol $50 \mu \mathrm{g}$ day $2.31 \mathrm{~L}$. Patient No. $15 \mathrm{did}$ not fully reach the stepwise reversibility test for inclu- sion (second improvement 49\% instead of defined 50\%), but was still included because the discrepancy was not considered to be of importance. The mean inhalation flow for the active devices was 68.1, 79.0 and 80.0 $\mathrm{L} \cdot \mathrm{min}^{-1}$ for formoterol Turbuhaler ${ }^{\circledR}(6,12$ and $24 \mu \mathrm{g}$, respectively), and 93.8 for salmeterol Diskhaler® (50 $\mu \mathrm{g})$.

\section{Responders and onset}

The percentage of patients having an increase in FEV1 of at least $15 \%$ over baseline at different time-points within $1 \mathrm{~h}$ after inhalation of the study drug, is shown in figure 1a. The number of patients responding with an FEV1 of at least $15 \%$ over baseline within $60 \mathrm{~min}$ after dosing ("responders") was for formoterol 6, 12 and $24 \mu \mathrm{g} 12,19$ and 18 patients, respectively, for salmeterol 17 patients, and for placebo one patient. The median onset time (including all patients) was 12.4 min for formoterol $12 \mu \mathrm{g}, 3.6 \mathrm{~min}$ for formoterol $24 \mu \mathrm{g}$, and
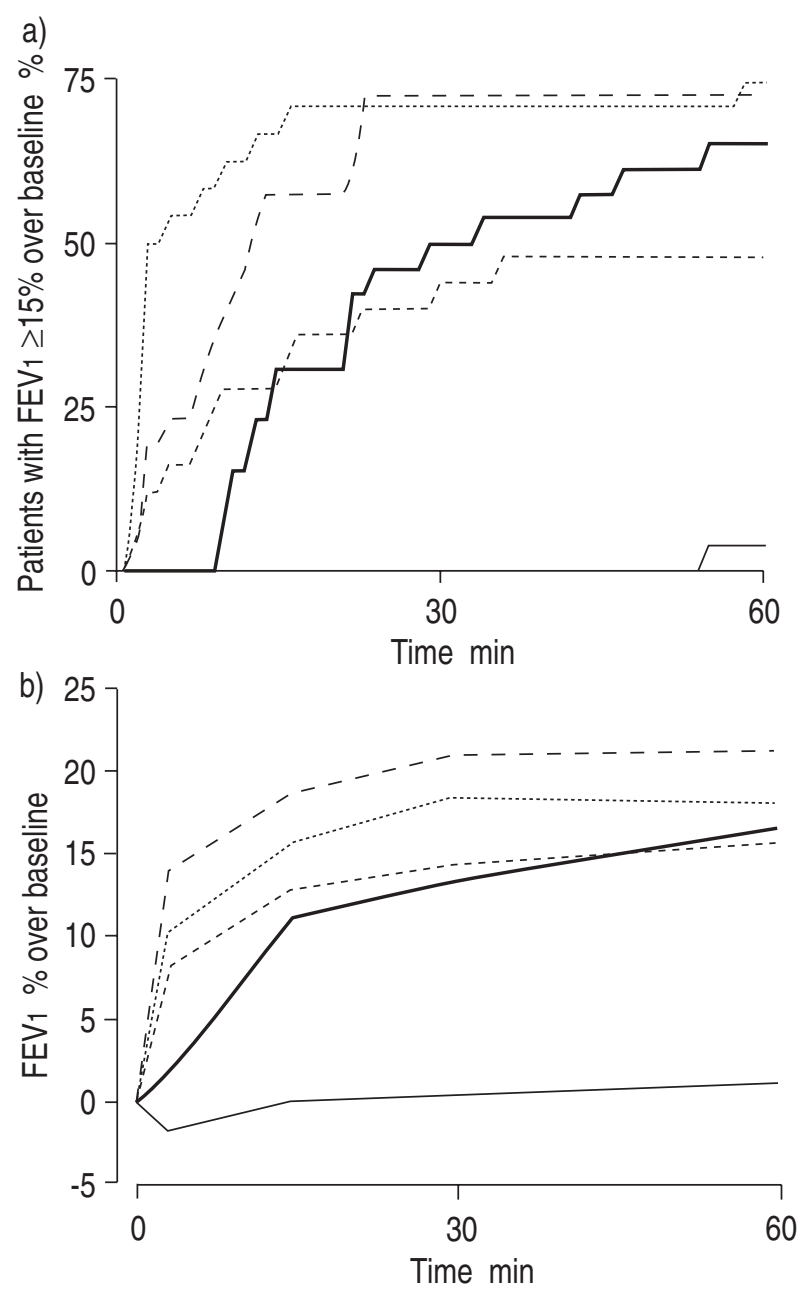

Fig. 1. - a) The probability (\% of patients) of having a clinically significant effect forced expiratory volume in one second ((FEV1) $\geq 15 \%$ over baseline) of formoterol $(6,12$ and $24 \mu \mathrm{g})$ and salmeterol $(50 \mu \mathrm{g})$ up to $1 \mathrm{~h}$ after inhalation, compared with placebo. b) Mean $\mathrm{FEV}_{1}$ (\% over baseline) after formoterol $(6,12$ and $24 \mu \mathrm{g})$ and salmeterol $(50 \mu \mathrm{g})$ up to $1 \mathrm{~h}$ after inhalation, compared with placebo.

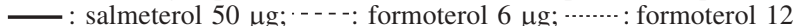
$\mu \mathrm{g} ;-$ - - : formoterol $24 \mu \mathrm{g} ;-\frac{}{-}$ : placebo. 
$31.0 \mathrm{~min}$ for salmeterol $50 \mu \mathrm{g}$. For formoterol $6 \mu \mathrm{g}$, less than half of the patients responded within $1 \mathrm{~h}$. When evaluating the onset time, Wilcoxon's signed rank test showed that formoterol 12 and $24 \mu \mathrm{g}$ had a more rapid onset of action compared with salmeterol $50 \mu \mathrm{g}(\mathrm{p}<0.05)$. With this test, the onset of action of the lowest dose of formoterol $(6 \mu \mathrm{g})$ could not be discriminated from the effect of salmeterol $50 \mu \mathrm{g}$, because of the low number of responders with formoterol $6 \mu \mathrm{g}$ compared with salmeterol. However, when analysing mean FEV1 data over the first hour (fig. 1b), a clearer difference between formoterol $6 \mu \mathrm{g}$ and salmeterol $50 \mu \mathrm{g}$ can be found, for example, at $3 \mathrm{~min}$ after dosing, all doses of formoterol caused a statistically significant better effect compared with salmeterol (fig. $1 \mathrm{~b} ; \mathrm{p}<0.05$ ). However, at $15 \mathrm{~min}$, formoterol 12 and $24 \mu \mathrm{g}$ caused a statistically significant greater improvement of FEV1 than salmeterol 50 $\mu \mathrm{g}$, whereas no significant difference was found between salmeterol and formoterol $6 \mu \mathrm{g}$ (fig. 1b).

\section{Duration of effect}

The time course of mean percentage change in FEV1 over the $12 \mathrm{~h}$ observation, including all patients, is shown in figure 2. All doses of formoterol and salmeterol caused improvement in FEV1, reaching peak values at approximately 1-3 h after dosing, and subsequently a slow drop in FEV1 was observed. The arithmetic mean duration of at least $15 \%$ increase in FEV1 compared with baseline (including only responders) was 244, 337, and $459 \mathrm{~min}$ after formoterol 6,12 and $24 \mu \mathrm{g}$, respectively, and $345 \mathrm{~min}$ after salmeterol $50 \mu \mathrm{g}$. Comparing the treatments, using zero as duration for nonresponders, formoterol 6 and $12 \mu \mathrm{g}$ had similar duration of effect compared with salmeterol $50 \mu \mathrm{g}$, whereas formoterol 24 $\mu \mathrm{g}$ had a numerically but not statistically significantly longer duration of effect than salmeterol $(\mathrm{p}=0.051)$. When analysing the mean residual FEV1 values for all patients at $12 \mathrm{~h}$ after dosing, all doses of formoterol and salmeterol $50 \mu \mathrm{g}$ produced significantly higher FEV1 compared with placebo. The FEV1 at $12 \mathrm{~h}$ was for formoterol

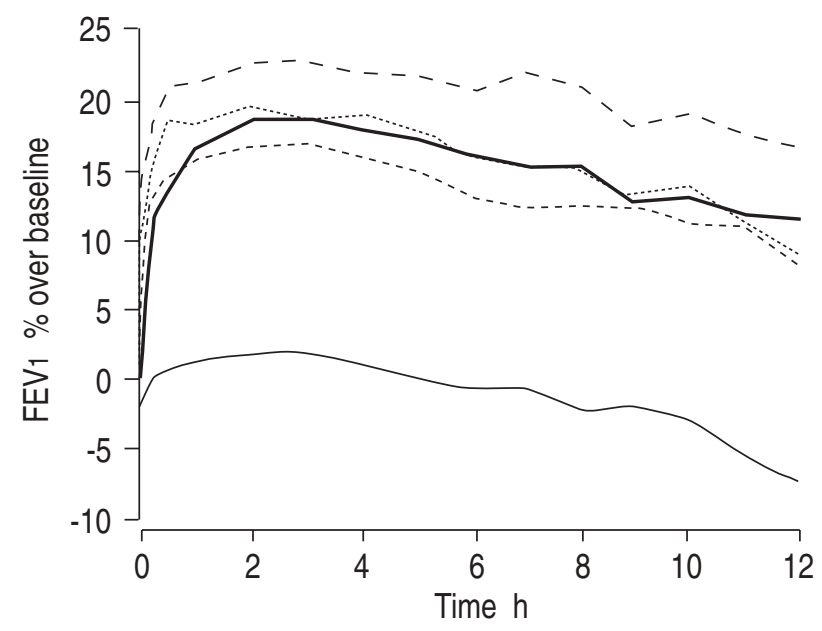

Fig. 2. - Mean forced expiratory volume in one second (FEV1) (\% over baseline) after formoterol $(6,12$ and $24 \mu \mathrm{g})$ or salmeterol (50 $\mu \mathrm{g})$ up to $12 \mathrm{~h}$ after inhalation, compared with placebo. - : sal-

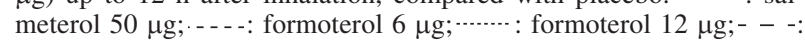
formoterol $24 \mu \mathrm{g} ; \_$: placebo.

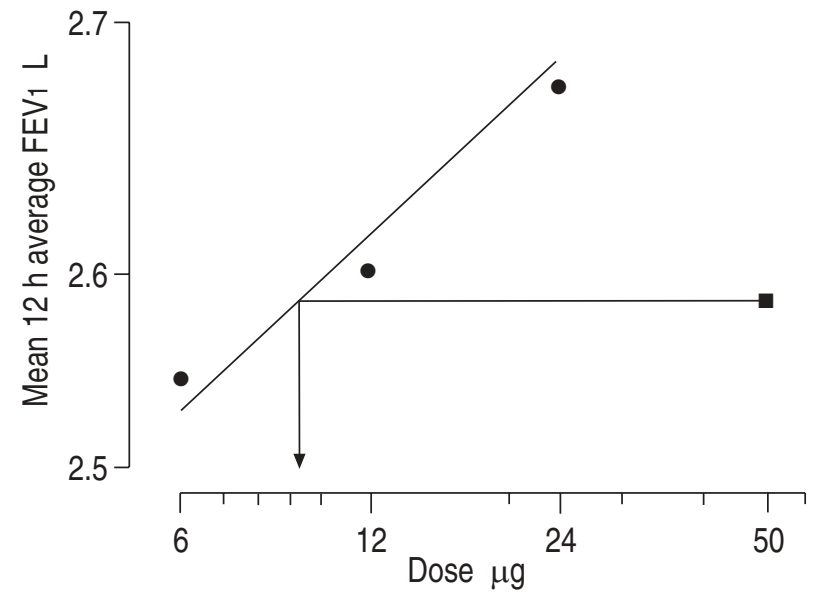

Fig. 3. - Average forced expiratory volume in one second (FEV1) (geometric mean) over $12 \mathrm{~h}$ after formoterol $(6,12$ and $24 \mu \mathrm{g})$ and salmeterol $(50 \mu \mathrm{g})$, and comparison of potency by fitting a straight line to the average FEV1. salmeterol $50 \mu \mathrm{g}$ is estimated to be equipotent to $9 \mu \mathrm{g}$ formoterol (3-19 $\mathrm{mg})$. $\mathbf{~}$ : salmeterol; $\bullet$ : formoterol.

$24 \mu \mathrm{g}$ significantly higher than the two lower doses of formoterol $(\mathrm{p}<0.05)$, but not compared with salmeterol $50 \mu \mathrm{g}$ (fig. 2).

\section{Dose comparisons}

The mean $12 \mathrm{~h}$ average FEV1 (primary variable) was for placebo $2.23 \pm 0.62$, for formoterol $2.62 \pm 0.68,2.68 \pm$ $0.68,2.71 \pm 0.70(6,12$ and $24 \mu \mathrm{g}$, respectively), and for salmeterol $50 \mu \mathrm{g} 2.65 \pm 0.62 \mathrm{~L}$. When relative potency of salmeterol was estimated by fitting a straight line to the $12 \mathrm{~h}$ average FEV1 after the three formoterol doses, salmeterol $50 \mu \mathrm{g}$ was estimated to be equipotent with $9 \mu \mathrm{g}$ formoterol. This value was not significantly different from 6 or $12 \mu \mathrm{g}$ of formoterol when evaluating the 95\% CIs (3-19 mg; fig. 3). However, formoterol 24 $\mu \mathrm{g}$ was significantly more potent than salmeterol $50 \mu \mathrm{g}$ $(\mathrm{p}<0.05)$.

\section{Adverse reactions}

The mean values of cardiac frequency did not increase over the study day compared with placebo (data not shown). The most common adverse event reported was headache, which was observed in six to seven patients after all treatments, including placebo. Typical $\beta_{2}$-receptor-mediated subjective symptoms (reported as adverse reactions) (tachycardia/palpitation and tremor) were not reported in any patients after placebo or salmeterol, but occurred with mild or moderate degree in one, one and five patients after formoterol 6,12 and $24 \mu \mathrm{g}$, respectively.

\section{Discussion}

This study shows that formoterol dry powder given via Turbuhaler®, causes a dose-dependent and rapid bronchodilation with a duration of action of at least 12 h. Formoterol has a more rapid onset of action compared with salmeterol. Furthermore, the data suggest 
that formoterol $12 \mu \mathrm{g}$ given via Turbuhaler® is approximately equipotent with salmeterol $50 \mu \mathrm{g}$ given via Diskhaler®.

Only limited data of direct comparisons between salmeterol and formoterol in clinical studies have been available. The slow onset of action of salmeterol in the present study confirms previous in vitro and clinical studies [9, 11-14]. Furthermore, in the present study, the rapid onset of action of formoterol is confirmed [15-17]. In fact, in the present study, all doses of formoterol produced a statistically significant improvement in lung function $3 \mathrm{~min}$ after inhalation, compared with salmeterol. With comparison to placebo, salmeterol also produced an improvement in lung function 3 min after inhalation. Fifteen min after inhalation, the effect of salmeterol $50 \mu \mathrm{g}$ approached the effects of the lowest dose of formoterol. It could be argued that formoterol, but perhaps not salmeterol, can be used as occasional rescue medication in asthma. However, the safety of such a treatment has not been studied.

It has been speculated that the duration of effect of salmeterol may last longer than that of formoterol, which seems to be the case in vitro $[18,19]$. However, in the present study, almost equipotent doses of formoterol and salmeterol (12 and $50 \mu \mathrm{g}$, respectively) caused very similar bronchodilation at $12 \mathrm{~h}$, arguing that formoterol and salmeterol have a similar duration of effect. It should be emphasized that both drugs most likely have a substantially longer duration of action than $12 \mathrm{~h}$, but because of the large differences between the treatments and the placebo at this time-point, further studies are required to evaluate this. At the highest dose of formoterol (24 $\mu \mathrm{g}$ ), it seems that the improved maximal effect also results in a prolonged duration of action, compared to the lower doses of the same drug, although the decline of the effect compared to placebo does not seem to be different between the treatments (fig. 2). This finding is in parallel with a recently published study [17], showing a very similar off-set of action of salmeterol and formoterol.

When comparing potency between different drugs, it is very important to use several doses of at least one of the compounds which are compared often. Direct comparisons between formoterol and salmeterol have utilized single doses of each drug [17], which is not sufficient for potency comparisons. In the present study it was estimated that salmeterol $50 \mathrm{mg}$ was equipotent with formoterol $9 \mu \mathrm{g}$ (95\% CI: 3-19 $\mu \mathrm{g}$ ). The inhaled dose of formoterol $12 \mu \mathrm{g}$ and salmeterol $50 \mu \mathrm{g}$ showed similar values for average FEV1 over $12 \mathrm{~h}$, as well as peak FEV1. Thus, the clinical dose relationship between formoterol and salmeterol was found to be similar to that proposed by indirect comparisons $[2,9]$. It is often difficult to show dose-related bronchodilation in clinical studies. In many patients, only a low dose of a $\beta_{2}$ agonist is required to reach maximal bronchodilating effect. It should be emphasized that we have included only patients with a stepwise bronchodilator response to a short-acting $\beta_{2}$-agonist, which may be important for our findings of dose-related bronchodilation with formoterol.

$\beta_{2}$-receptor-mediated adverse events such as tremor and tachycardia were mild and occurred in very few patients, except after the highest dose of formoterol.
This argues that such doses, after single inhalation, are well tolerated.

In the present study, salmeterol was delivered by the dry-powder Diskhaler® device, whereas formoterol was delivered by the Turbuhaler ${ }^{\circledR}$. Turbuhaler ${ }^{\circledR}$ has previously been suggested to deliver higher amounts of salbutamol to the airways than other inhalation devices such as pMDI or Diskhaler® $[20,21]$. Thus, it should be emphasized that this study does not give us a direct comparison of the two chemical entities in the asthmatic airways in vivo, as delivery and distribution of drug in the airway tree may differ, due to the use of two different inhalation devices.

Formoterol and salmeterol are both potent, efficacious and long-acting bronchodilators, with few and mild sideeffects at recommended doses. Perhaps the most important difference of these drugs, shown in the present study, is that formoterol has a more rapid onset.

Acknowledgements: The authors are grateful to $\mathrm{H}$. Törnqvist, E. Karlgren, K. Evby and V. Nilsson, for their technical assistance.

\section{References}

1. Ullman A, Svedmyr N. Salmeterol, a new long acting inhaled beta-2-agonist: a comparison with salbutamol. Thorax 1988; 43: 674-678.

2. Löfdahl CG, Svedmyr N. Formoterol fumarate, a new beta-2-adrenoceptor agonist. Allergy 1989; 44: 246-271.

3. Lötvall J, Svedmyr N. Salmeterol: An inhaled beta-2agonist with prolonged duration of action. Lung 1993; 171: 249 .

4. Rabe KF, Jörres R, Nowak D, Behr N, Magnussen H. Comparison of the effects of salmeterol and formoterol on airway tone and responsiveness over 24 hours in bronchial asthma. Am Rev Respir Dis 1993; 147: 1436-1441.

5. Fitzpatrick MF, Mackay T, Driver H, Douglas NJ. Salmeterol in nocturnal asthma: a double-blind placebo controlled trial of a long acting inhaled beta-2-agonist. Br Med J 1990; 301: 1365-1368.

6. Arvidsson P, Larsson S, Löfdahl CG, Melander B, Wåhlander L, Svedmyr N. Inhaled formoterol during one year in asthma. A comparison with salbutamol. Eur Respir J 1991; 4: 1168-1173.

7. Kesten S, Chapman KR, Broder I, et al. A three-month comparison of twice daily inhaled formoterol versus four times daily inhaled albuterol in the management of stable asthma. Am Rev Respir Dis 1991; 144: 622-625.

8. Greening AP, Ind PW, Northfield M, Shaw G. Added salmeterol versus higher-dose corticosteroid in asthma patients with symptoms on existing inhaled corticosteroid. Lancet 1994; 344: 219-224.

9. Lötvall J, Lunde H, Hedner J, Svedmyr N. Onset of bronchodilation and tremor inducing effect of salmeterol and salbutamol (albuterol) up to two hours after inhalation. Am Rev Respir Dis 1994; 149: A206 (suppl).

10. Wegener T, Hedenström H, Melander B. Rapid onset of action of inhaled formoterol in asthmatic patients. Chest 1992; 102: 535-538.

11. Linsen VMJ, Bindels HJC, van Nord JA. A direct comparison of the time of onset of action between inhaled formoterol and salmeterol. Eur Respir J 1993; 6 (Suppl. 17): 591. 
12. Ball DI, Brittain RT, Coleman RA, et al. Salmeterol, a novel, long-acting beta-2-adrenoceptor agonist: characterization of pharmacological activity in vitro and in vivo. Br J Pharmacol 191; 104: 665-671.

13. Ullman A, Bergendal A, Lindén A, Waldeck B, Skoogh B-E, Löfdahl C-G. Onset of action and duration of effect of formoterol and salmeterol compared with salbutamol in isolated guinea pig trachea with or without epithelium. Allergy 1992; 47: 384-387.

14. Jeppsson AB, Nilsson E, Waldeck B. Formoterol and salmeterol are both long acting compared to terbutaline in the isolated perfused guinea pig lung. Eur J Pharmacol 1994; 257: 137-143.

15. Wallin A, Sandström T, Rosenhall L, Melander B. Time course and duration of bronchodilation with formoterol dry powder in patients with stable asthma. Thorax 1993; 48: 611-614.

16. Ringdal N, Derom E, Pauwels R. Onset and duration of action of single doses of formoterol inhaled via Turbuhaler in mild to moderate asthma. Eur Respir J 1995; 8: Suppl. $19,68 \mathrm{~s}$.
17. van Noord J, Smeets JJ, Raaijmakers JAM, Bommer AM, Maesen FPV. Salmeterol versus formoterol in patients with moderately severe asthma: onset and duration of action. Eur Respir J 1996; 9: 1684-1688.

18. Lindén A, Bergendal A, Ullman A, Skoogh B-E, Löfdahl C-G. Salmeterol, formoterol and salbutamol in the isolated guinea pig trachea: differences in maximum relaxant effect and potency but not in functional antagonism. Thorax 1993; 48: 547-553.

19. Naline E, Zhang Y, Qian Y, et al. Relaxant effects and durations of action of formoterol and salmeterol on the isolated human bronchus. Eur Respir J 1994; 7: 914-920.

20. Löfdahl C-G, Andersson L, Carlsson LG, et al. Lower nominal dose required of inhaled salbutamol via Turbuhaler compared with pressurized metered-dose inhaler, for the same bronchodilating effect. Am Resp Crit Care Med 1994; 149: A219.

21. Hörnblad V, Jemsby P, Rosenborg J, Werner S, Svedmyr N. Salbutamol doses inhaled via Turbuhaler gives a better bronchodilating effect than given via pressurised metered dose inhalers. Eur Respir J 1994; 7: Suppl. 18, 49S. 